\title{
Effect of Drying-Wetting Cycles on Saturated Shear Strength of Undisturbed Residual Soils
}

\author{
Sayem Hossain Md ${ }^{1,2,}$, Kong Ling-wei ${ }^{1}$, Yin Song ${ }^{1}$ \\ ${ }^{1}$ State Key Laboratory of Geomechanics and Geotechnical Engineering, Institute of Rock and Soil Mechanics, Chinese Academy of Sciences, \\ Wuhan, Hubei, China \\ ${ }^{2}$ Department of Geological Sciences, Jahangirnagar University, Dhaka, Bangladesh
}

Email address:

sayem_geo@yahoo.com (Sayem H. M.), lwkong@whrsm.ac.cn (Kong L. W.), flysong1314@126.com (Yin S.)

${ }^{*}$ Corresponding author

\section{To cite this article:}

Sayem Hossain Md, Kong Ling-wei, Yin Song. Effect of Drying-Wetting Cycles on Saturated Shear Strength of Undisturbed Residual Soils. American Journal of Civil Engineering. Vol. 4, No. 4, 2016, pp. 159-166. doi: 10.11648/j.ajce.20160404.15

Received: April 10, 2016; Accepted: May 14, 2016; Published: June 2, 2016

\begin{abstract}
Due to world-wide distributions and extensively used as construction materials, geotechnical engineers are interested in understanding the mechanical behavior of residual soils which are sometimes referred in the literature as problematic soils. The climatic zones where residual soils occur are often experienced by many drying-wetting cycles due to seasonal variations. This seasonal variation in the water content termed as drying-wetting cycle is regarded as the most destructive environmental factor that may cause many foundation diseases. Considering these, the purpose of this study is to understand the effects of drying-wetting cycles on saturated shear strength characteristics of undisturbed residual soil. A series of consolidated drained (CD) triaxial tests are conducted on multiple drying-wetting soil specimens to analyze the saturated shear strength. The test results indicate that the stress-strain relationships appear to be strain-hardening. The deviatory stress and initial stiffness of saturated soils increase and the volume of soils becomes contractive as the net normal stress increases but decrease with increasing drying-wetting cycle numbers. The cohesion $\left(c_{d}\right)$ and internal friction angle $\left(\varphi_{d}\right)$ decrease with increasing cycle number $(\mathrm{N})$ but the attenuation rate of $\varphi_{\mathrm{d}}$ is less than $\mathrm{c}_{\mathrm{d}}$. The variations of $\mathrm{c}_{\mathrm{d}}$ and $\varphi_{\mathrm{d}}$ with respect to drying-wetting cycles can be expressed by exponential function. The saturated shear strength and it's attenuation rate due to drying-wetting cycles are analyzed. The effect is more significant for the first cycle and decreases with subsequent cycles and finally reaches to a constant state after 4 cycles. Furthermore, a mathematical function is proposed in this paper which can describe the saturated shear strength attenuation rate of drying-wetting cycle samples. Such studies are useful to understand the possible changes in shear strength behavior of residual soils below the engineering structures that are subject to periodic drying and wetting from climatic variations.
\end{abstract}

Keywords: Drying-Wetting Cycle, Residual Soil, Shear Strength, Attenuation Rate

\section{Introduction}

Residual soils are the weathering product of their parent materials. The engineering properties and behavior of residual soils vary widely from place to place even within depth depending upon the rock of origin and the local climate during their formation. These soils are found in many parts of the world (for example in Bangladesh, China, India, Malaysia, Singapore, Thailand etc) and are used extensively in construction, either to build upon, or as construction material of both geotechnical and geoenvironmental structures such as embankments, pavements, earth fills and soil barriers. Therefore, geotechnical engineers are interested in understanding the mechanical behavior of residual soils which are sometimes referred in the literature as problematic soils.

Due to world-wide distributions and extensively used as construction materials, many research worked have already been done on residual soils. For example, the engineering characteristics, microfabric and mineralogical composition, degree of weathering, compressibility and shear strength properties and their controlling factors, bonding behavior and its loading impact, stiffness or yielding behavior of both 
natural and compacted residual soils are examined by numerous scholars [1-11]. Several geo-engineering problems associated with residual soils such as landslides, subsidences, damage of road and railway tract, building collapse in many parts of the world have also been reported.

Under extreme climatic conditions such as heavy rainfall, persistent drought and multiple drying-wetting cycles will cause many engineering problems including the weakening of the mechanical properties in consequence foundation diseases. Based on a large amount of investigations, climatic condition, namely drying-wetting, is regarded as the most destructive environmental factor that can induce damage to infrastructures such as highways and pavements [12-13].

A significant number of investigations have been conducted to understand the effects of drying-wetting cycles on soil physical and mechanical properties. It is found that drying-wetting cycle is one of the important factors to impact soil fabric, particle cementation, water content, and void ratio of soils [14-20]. This effect leads to the formation of cracks as well as the development of fissures in soils which significantly increase soil compressibility [21-23]. The hydraulic conductivity or permeability coefficient increases with increasing drying-wetting cycles of compacted clay cover but decreases if the soil is improved with the addition of lime [24-25]. The strength change of expansive soil under drying-wetting cycles plays an important role in the slope stability analysis. The shear strength of expansive soils decreases with the increasing number of cycles, the cohesion of expansive soil decreases obviously and the friction angle keeps a stable value. Furthermore, the slope stability and safety factor decrease with increasing number of cycles [26-27]. Several authors showed that the influence of the first drying-wetting cycle on soil structure is greatest and decreases with subsequent cycles [28-30]. The study on lime or fly ash stabilized expansive soils or solidified sludge found that drying-wetting cycles may lead to increase in swelling percent, liquid limit and plasticity index, and a reduction in plastic limit and soil strength [31-32].

Recently, the effects of drying-wetting cycles on soil strength profile of a silty clay are investigated using a micro-penetrometer and found that the strength tends to decrease with increasing cycles and the reduction between the $1^{\text {st }}$ and $2^{\text {nd }}$ drying paths is much higher than that between the $2^{\text {nd }}$ and $3^{\text {rd }}$ drying paths. The pattern of the penetration curve changes from typical mono-peak to multi-peak pattern after the $3^{\text {rd }}$ drying-wetting cycles which reflects that the drying-wetting cycles create more defects in soil microstructure and intensify the heterogeneity of strength in profile [33-34].

Most of the previous investigations on the effects of multiple drying-wetting cycles on engineering properties are based on expansive soil or artificial soils (soil mixed with fly ash, cement, lime or organic polymers) or reconstructed soils for the purpose of slope stability analysis or soil solidification or stabilization. But the effects of multiple drying-wetting cycles on shear strength of undisturbed residual soils are not well understood yet. Therefore, the main objective of this study is to evaluate the effects of drying and wetting cycles on saturated shear strength of undisturbed residual soils.

\section{Materials and Methods}

Undisturbed residual soil samples of $5.0-7.0 \mathrm{~m}$ depths collected at areas around Kaiping, Gaungdong, China are used for this study. According to X-ray diffraction analysis, the studied soils are mainly composed of kaolinite with small amount of illite. The non-clay minerals include quartz, pyrite and gibbsite. The basic material properties are measured in the laboratory and given in table 1 and the grain size distribution is shown in Fig. 1.

Table 1. Basic material properties of the studied residual soils.

\begin{tabular}{|c|c|c|c|c|c|c|c|c|c|c|}
\hline \multirow{2}{*}{ Depth (m) } & \multirow{2}{*}{$P_{d}\left(g / \mathrm{cm}^{3}\right)$} & \multirow{2}{*}{ NMC \% } & \multicolumn{3}{|c|}{ Atterberg limits } & \multirow{2}{*}{ Free swell (\%) } & \multicolumn{4}{|c|}{ Grain size distribution (\%) } \\
\hline & & & $\mathrm{L}_{\mathrm{L}} \%$ & $\mathbf{P}_{\mathrm{L}} \%$ & $\mathbf{I}_{\mathrm{P}} \%$ & & Gravel & Sand & Silt & Clay \\
\hline $5.7 \sim 6.0$ & 1.30 & 40.2 & 57.1 & 30.7 & 26.4 & 9.75 & 4.6 & 33.4 & 45.9 & 16.1 \\
\hline
\end{tabular}

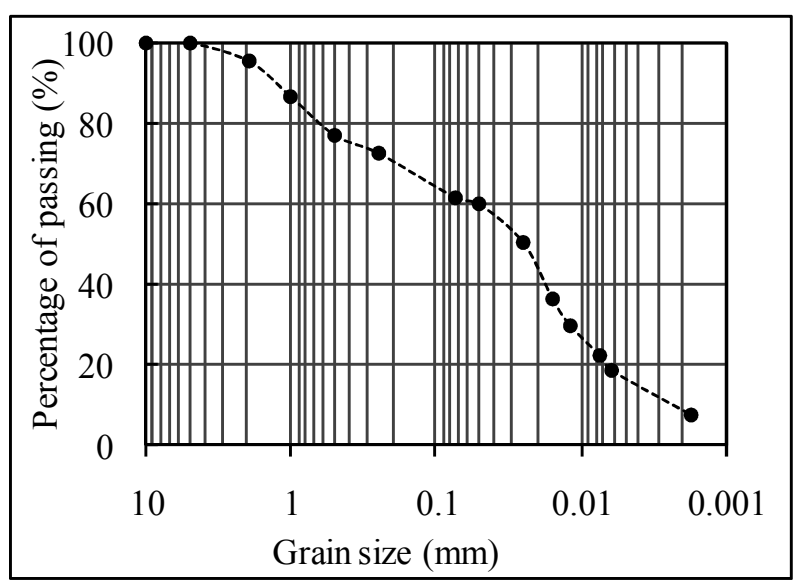

Figure 1. Grain size distribution of the studied residual soil.
The preparation procedures include cutting appropriate size of soil using cutting ring from the core samples. After cutting and weighted, the samples are dried up to moisture content $20 \%$ at a constant temperature of $40 \pm 2{ }^{\circ} \mathrm{C}$ (the highest temperature under simulated natural conditions). Remove the specimens from oven and allow 1-2 $\mathrm{h}$ for cool at room temperature. The samples are covered by filter paper and water-permeable stone both on top and bottom to prevent disturbance during the saturation process. Then the samples are saturated with distilled water after vacuum seeding about 2 hours and then submerged about $24 \mathrm{~h}$. Later the samples are dried up to $20 \%$ moisture content oven at a constant temperature of $40 \pm 2^{\circ} \mathrm{C}$. This is one drying-wetting cycle. The process is repeated until the desired numbers of drying-wetting cycles $(0,1,2,4$ and 8$)$ are completed. 
A conventional triaxial test apparatus is used to measure the shear strength parameters of saturated drying-wetting soil specimens under consolidated drained (CD) conditions following the ASTM D7181-11 [35] standard test method. Prior to the tests, the soil specimens are saturated from the top until a value of B (the pore-water parameter) is $0.95( \pm 0.02)$ and it takes 2-4 days. For this purpose, the cell pressure and saturation water pressure (back pressure) are applied and then increased gradually. A difference of $10 \mathrm{kPa}$ between cell pressure and back pressure is maintained to prevent swelling or consolidation during the saturation process. After completing the saturation process, the soil specimens are consolidated under a confining pressure of $\sigma_{3}$, and pore water is allowed to drain out. The intervals of elapsed time $(0.25,0.5$ $1,2,3,4,5,10,15,30 \mathrm{~min}$ and at 1, 2, 4, and $8 \mathrm{~h}$, and so forth) and the corresponding volume change are recorded. The consolidation process is allowed to continue until a steady value of volume change is obtained. At the end of the consolidation, the specimens are sheared at a strain rate of $0.011 \% / \mathrm{min}$. For all the samples, the net confining pressures are of $50,100,200$ and $300 \mathrm{kPa}$ and shear strain upto $20 \%$.

\section{Results and Discussions}

The drained deviator stress versus axial strain curves for the drying-wetting cycle samples are shown in Fig. 2-6 and it can be seen that the stress-strain relationships appear to be strain-hardening. The curves show a maximum stress level in each case and after reaching the maximum stress level, there is a slight reduction or tends to reach a steady or equilibrium state in deviator stress with increasing strain. The results show that the peak deviatory stresses reduce with increasing drying-wetting cycles. The reduction is more pronounced in the $1^{\text {st }}$ cycle and decreases with subsequent cycles and finally reaches to a constant state after 4 cycles. The axial strains to attain maximum deviator stress for these drying-wetting samples show higher values range from 14.57-18.94\% which is a reflection of highly plastic nature of the soil.

The volumetric strain versus axial strain curves are shown in Fig. 7-11. It can be observed that all the samples show contraction behavior because of reduction in volume during drained shearing. It can also be seen that the amount of contraction varied from sample to sample.

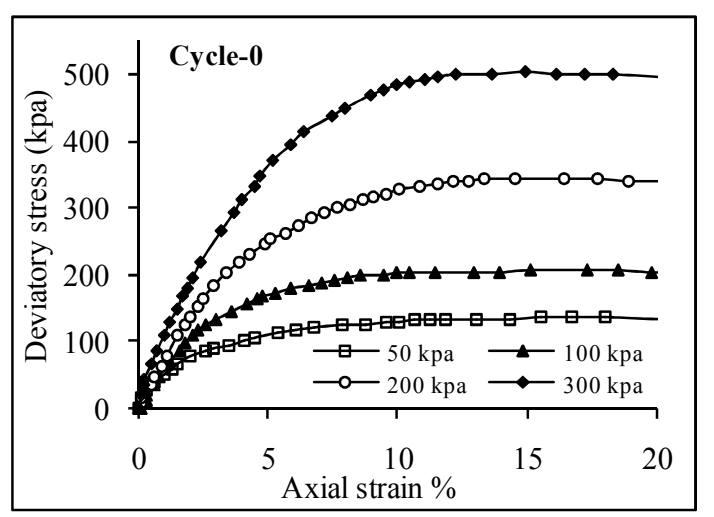

Figure 2. Deviatory stress versus axial strain curve of initial soil samples.

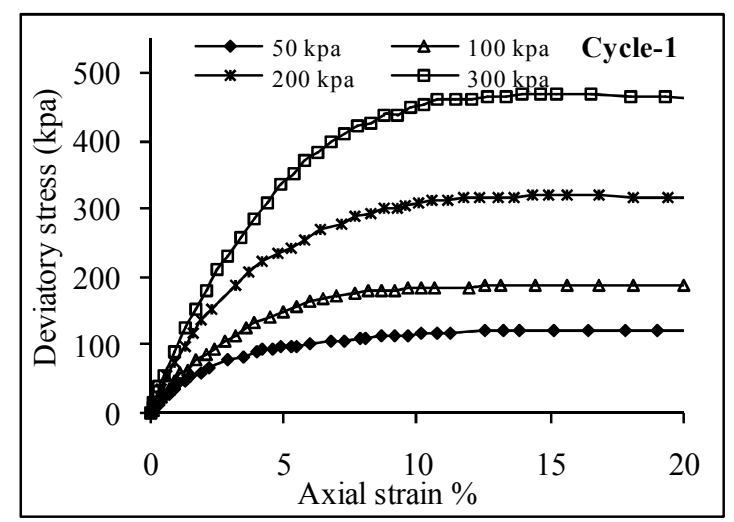

Figure 3. Deviatory stress versus axial strain of $1^{\text {st }}$ drying-wetting cycle.

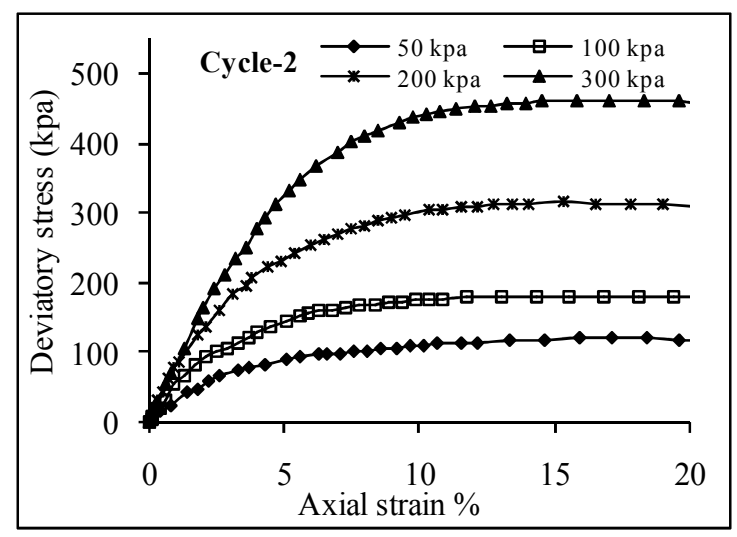

Figure 4. Deviatory stress versus axial strain of $2^{\text {nd }}$ drying-wetting cycle.

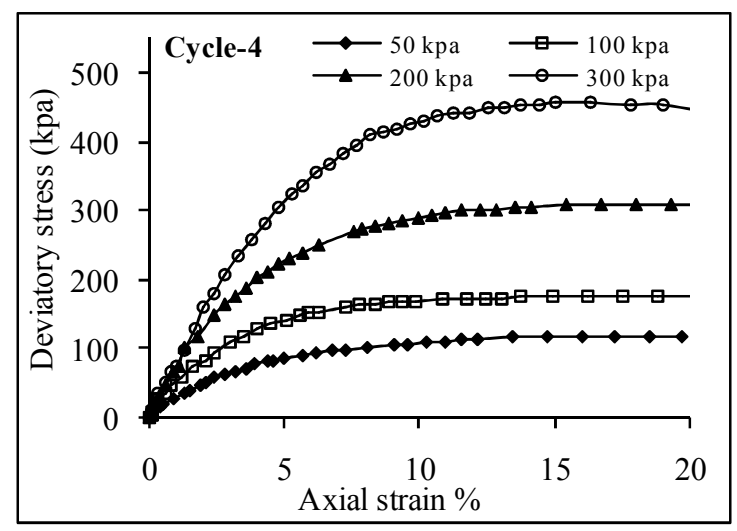

Figure 5. Deviatory stress versus axial strain of $4^{\text {th }}$ drying-wetting cycle.

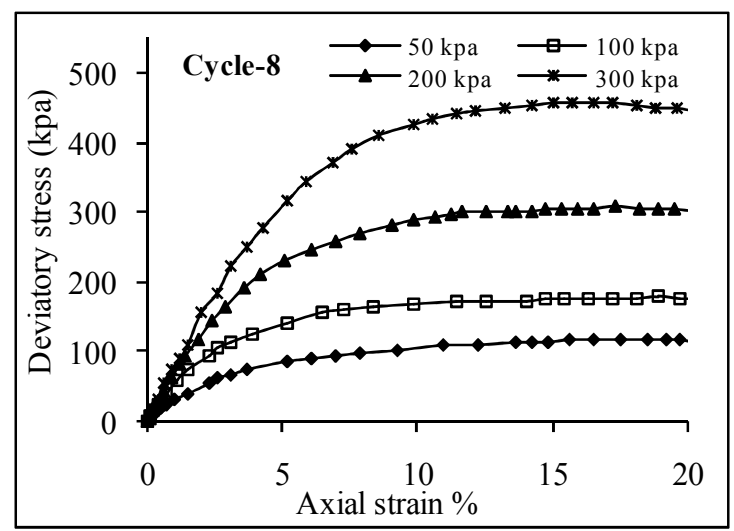

Figure 6. Deviatory stress versus axial strain of $8^{\text {th }}$ drying-wetting cycle. 


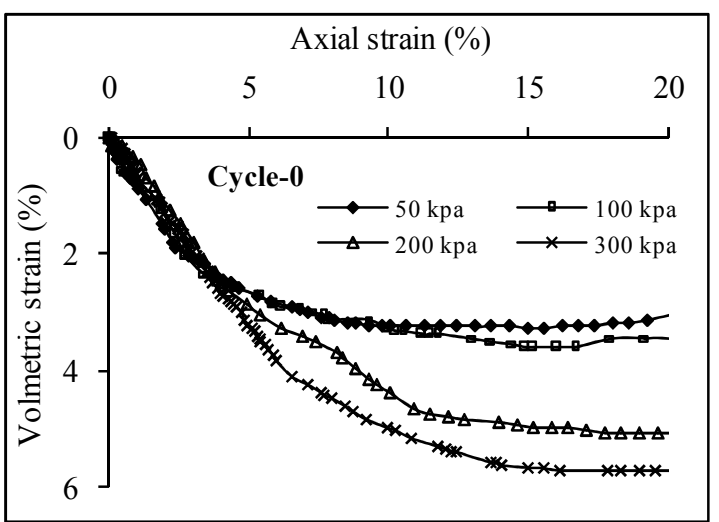

Figure 7. Volumetric strain versus axial strain curve of initial soil samples.

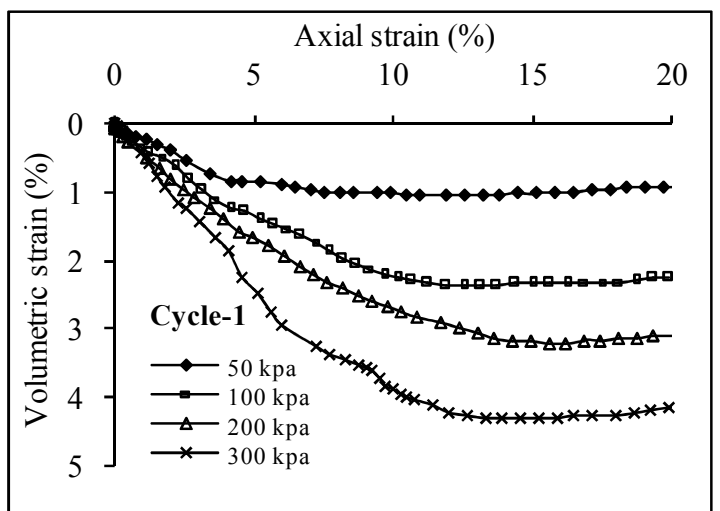

Figure 8. Volumetric strain versus axial strain of $1^{\text {st }}$ drying-wetting cycle.

After attaining a maximum contraction, the volumetric strain of each sample tends towards a steady value of the volumetric strain at very large strain and there is no distinct dilation behavior which suggesting that they might approach the critical state condition. The effective stress paths of those drying-wetting cycle samples are shown in Fig. 12-16. It is observed that the failure point and end point almost close to each other indicating the hardening behavior of the soil. All the samples failed with a number of indistinct shear planes and by bulging. At high net normal stress, the sample failed with distinct shear planes and prominent bulging. The possible critical state lines (CSL) and the slope of CSL (M) in the plane of deviator stress against mean effective stress of the saturated specimen are also given in Fig. 12-16.

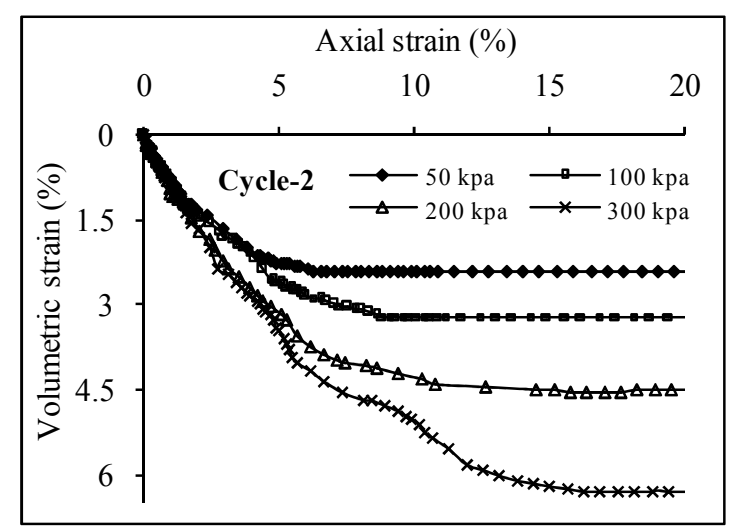

Figure 9. Volumetric strain versus axial strain of $2^{\text {nd }}$ drying-wetting cycle.

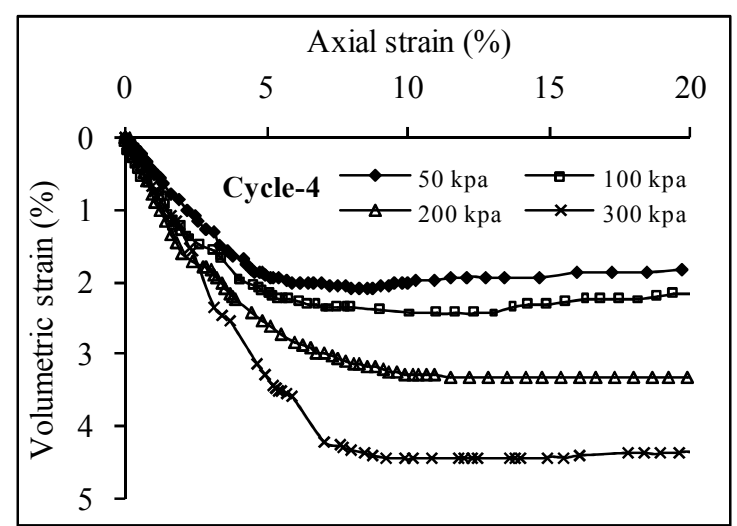

Figure 10. Volumetric strain versus axial strain of $4^{\text {th }}$ drying-wetting cycle.

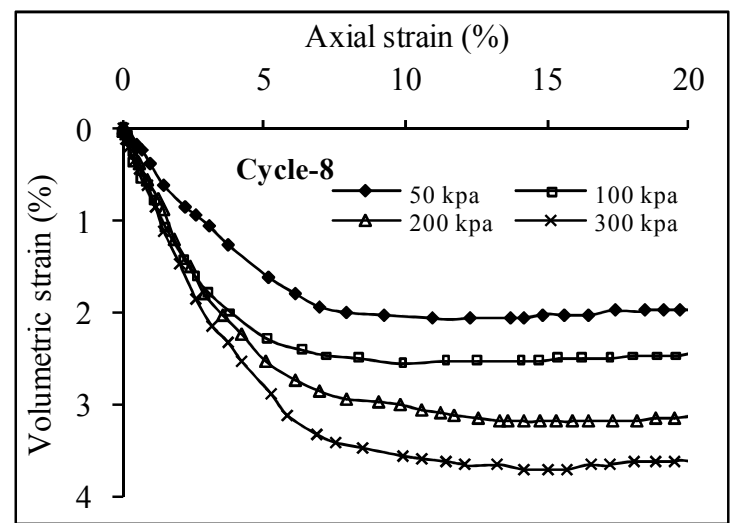

Figure 11. Volumetric strain versus axial strain of $8^{\text {th }}$ drying-wetting cycle.

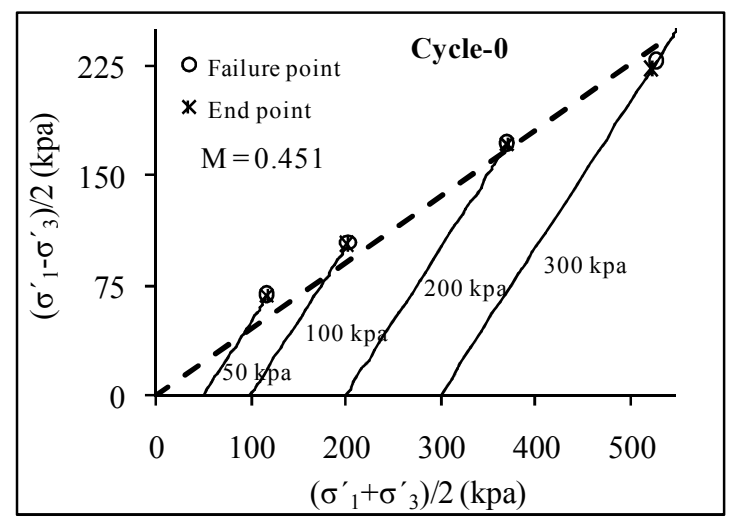

Figure 12. Effective stress paths of initial soil samples.

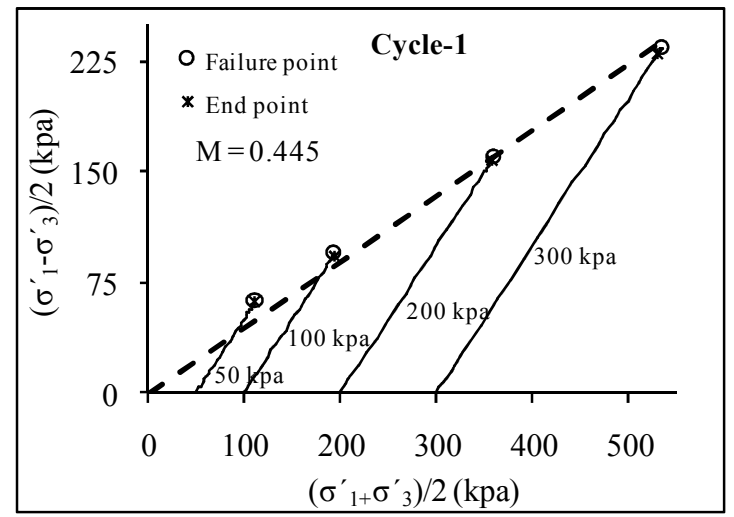

Figure 13. Effective stress paths of $1^{\text {st }}$ drying-wetting soil samples. 


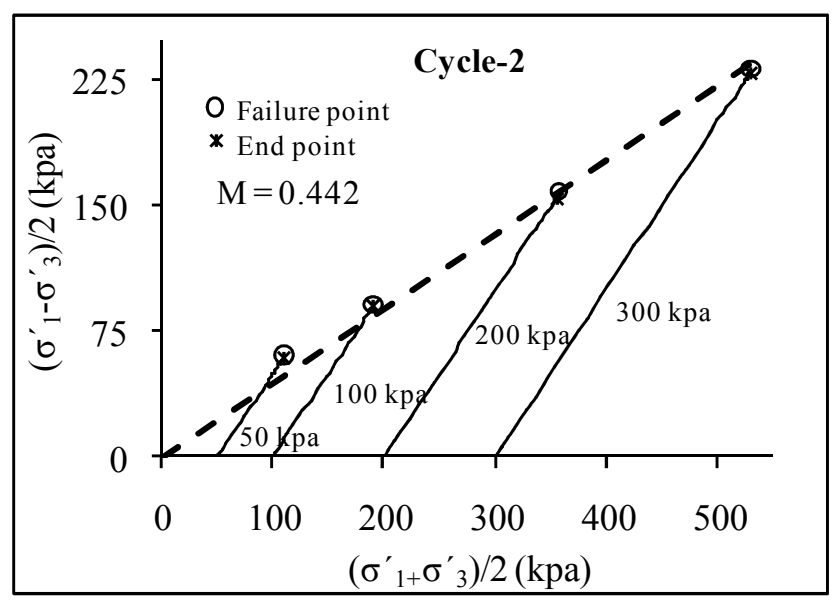

Figure 14. Effective stress paths of $2^{\text {nd }}$ drying-wetting soil samples.

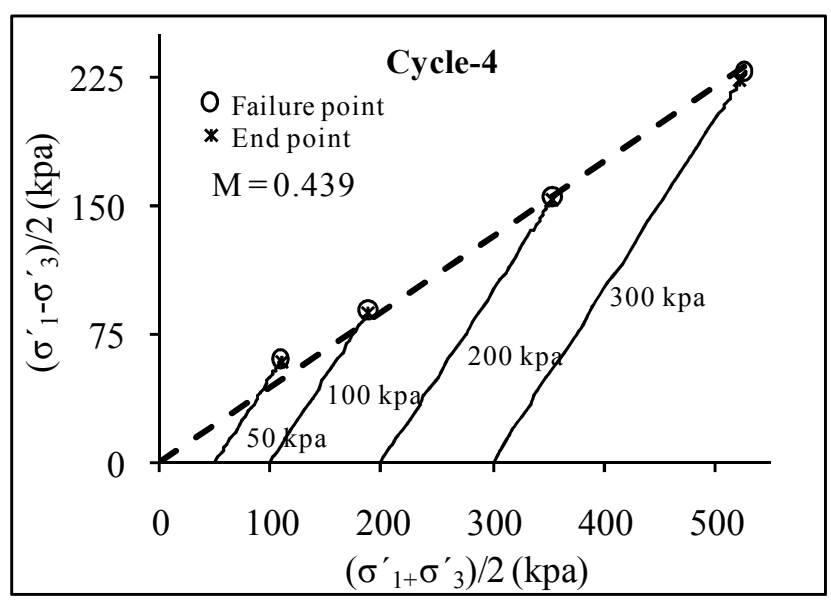

Figure 15. Effective stress paths of $4^{\text {th }}$ drying-wetting soil samples.

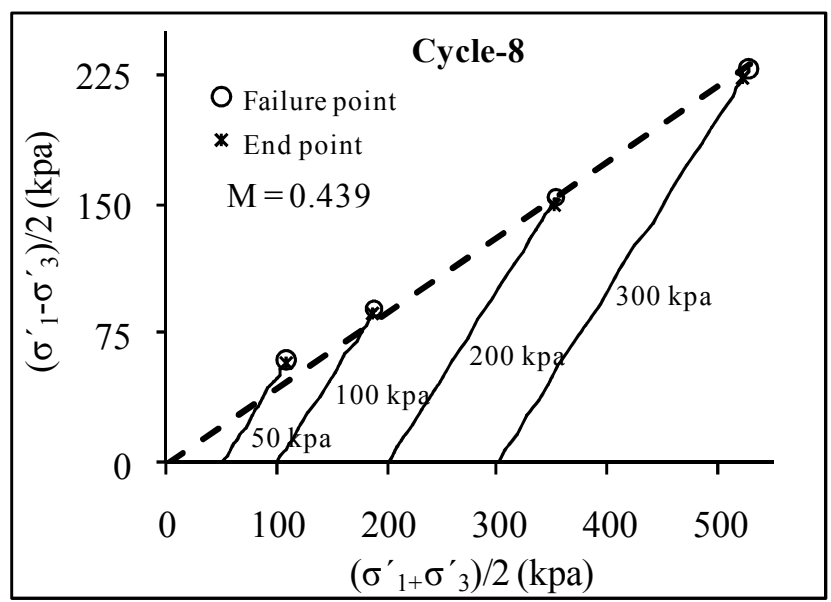

Figure 16. Effective stress paths of $8^{\text {th }}$ drying-wetting soil samples.

The deviatory stress and initial stiffness of saturated soils increase and the volume of soils becomes contractive as the net normal stress increases. The increase in the net normal stress may force soil particles to close pack arrangement (volume contraction) during shearing.

This volume contraction makes the sample denser, eventually the shear resistance and the initial stiffness increase. But the deviatory stress and initial stiffness of saturated soils decrease with increasing drying-wetting cycle numbers. The slope of the critical state line also decreases with increasing cycle numbers.

The saturated strength parameters $\left(c_{d}\right.$ and $\left.\varphi_{d}\right)$ of the drying-wetting cycles specimens are determined by the classical Mohr-Coulomb approach which are given in table 2. The failure envelope of the drying-wetting cycles is shown in Fig. 17. The cohesion $\left(c_{d}\right)$ and internal friction angle $\left(\varphi_{d}\right)$ decrease with increasing cycle number $(\mathrm{N})$ but the attenuation rate of $\varphi_{d}$ is less than $c_{d}$ (Fig. 17). The variations of $c_{d}$ and $\varphi_{d}$ with respect to drying-wetting cycles can be calculated using exponential function and the obtained results are fitted well with the measured $\mathrm{c}_{\mathrm{d}}$ and $\varphi_{\mathrm{d}}$ data (Fig. 18).

Table 2. Saturated shear strength parameters of drying-wetting cycles.

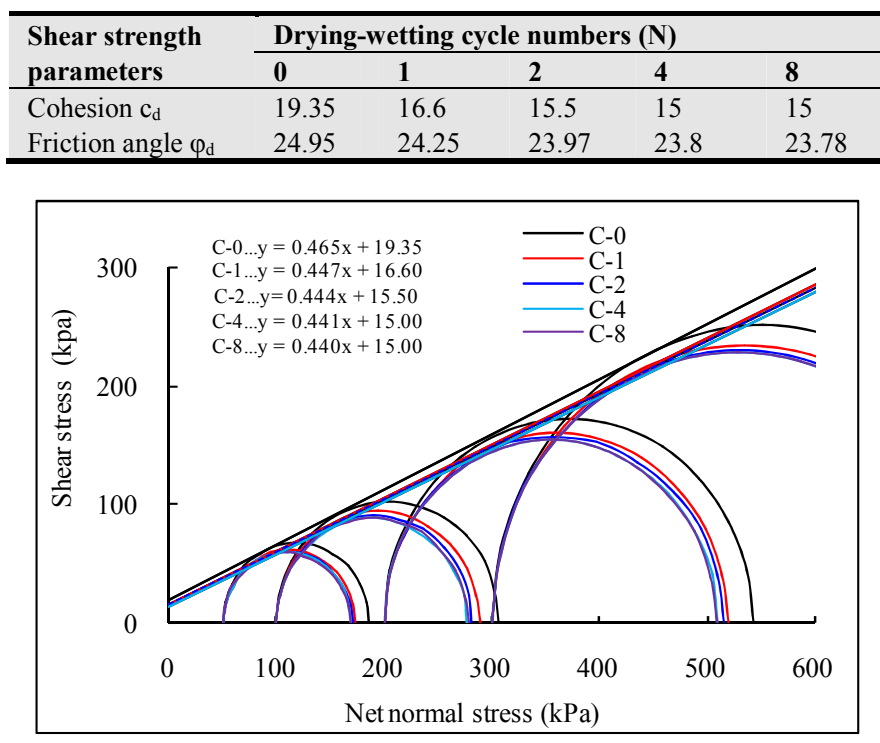

Figure 17. Mohr-Coulomb failure envelop of different drying-wetting cycles.

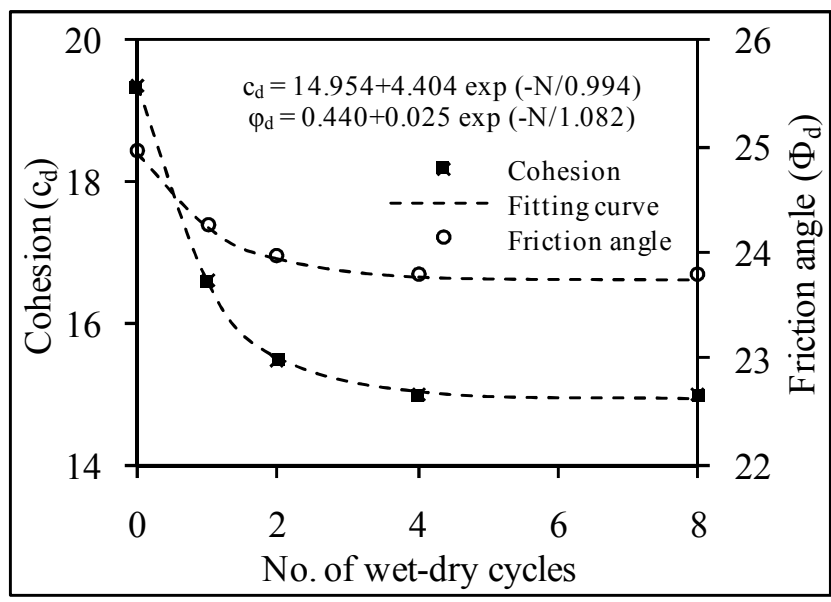

Figure 18. Variation of $c_{d}$ and $\varphi_{d}$ with respect to drying-wetting cycles.

The variations of saturated shear strength under different net normal stress and drying-wetting cycles are given in table 3 and found that the saturated shear strength increases with increasing net normal stress. It can also be seen that at same net normal stress, the shear strength decreases with increasing drying-wetting cycles. 
Table 3. $\tau_{\text {sat }}$ with different wetting-drying cycles and net normal stress.

\begin{tabular}{llllll}
\hline \multirow{2}{*}{$\left(\boldsymbol{\sigma}-\boldsymbol{\mu}_{\mathbf{a}}\right) / \mathbf{k p a}$} & \multicolumn{6}{l}{$\boldsymbol{\tau}_{\text {sat }}(\mathbf{k p a})$ with dry-wet cycles } \\
\cline { 2 - 6 } & $\mathbf{0}$ & $\mathbf{1}$ & $\mathbf{2}$ & $\mathbf{4}$ & $\mathbf{8}$ \\
\hline 50 & 42.6 & 39.1 & 37.7 & 37.05 & 37 \\
100 & 65.85 & 61.6 & 59.9 & 59.1 & 59 \\
200 & 112.4 & 106.6 & 104.3 & 103.2 & 103 \\
300 & 158.9 & 151.6 & 148.7 & 147.3 & 147 \\
\hline
\end{tabular}

The attenuation rate $(\%)$ of saturated shear strength with respect to drying-wetting cycles is calculated using following equation-

$$
\Delta_{\tau}=\frac{\left|\tau_{\mathrm{i}}-\tau_{0}\right|}{\tau_{0}} \times 100 \%
$$

Where, $\Delta_{\tau}$ is the attenuation rate $(\%), \tau_{0} \& \tau_{\mathrm{i}}$ are the saturated shear strength of initial and after different drying-wetting cycles respectively.

The variations of saturated shear strength attenuation rate (\%) under different net normal stress and drying-wetting cycles are given in table 4 . For example, at $50 \mathrm{kpa}$ confining pressure, the attenuation rate is $8.22 \%, 11.50 \%, 13.03 \%$, $13.15 \%$ for $1,2,4$ and 8 cycles respectively. The attenuation rate from cycle $0 \rightarrow 1,1 \rightarrow 2,2 \rightarrow 4$ and $4 \rightarrow 8$ are about $8.22 \%$, $2.78 \%, 1.53 \%$ and $0.12 \%$ respectively. It is stated that the attenuation rate is more pronounced in the first cycle and decreases with subsequent cycles and finally reaches to a constant state after 4 cycles. The attenuation rate also decreases with increasing net normal stress. This reduction of shear strength with drying-wetting cycles might be due to the changes of particle arrangement and the grain size distribution, decrease of pore volume and void ratio or due to the formation of micro-cracks and fissures.

Table 4. $\tau_{\text {sat }}$ attenuation rate (\%) with different wetting-drying cycles and net normal stress.

\begin{tabular}{lllll}
\hline \multirow{2}{*}{$\left(\boldsymbol{\sigma}-\boldsymbol{\mu}_{\mathbf{a}}\right) / \mathbf{k p a}$} & \multicolumn{4}{c}{$\boldsymbol{\tau}_{\mathbf{s a t}}$ attenuation rate $(\boldsymbol{\%})$} \\
\cline { 2 - 5 } & $\boldsymbol{\Delta}_{\mathbf{c}-\mathbf{1}}$ & $\boldsymbol{\Delta}_{\mathbf{c}-\mathbf{2}}$ & $\boldsymbol{\Delta}_{\mathbf{c}-\mathbf{4}}$ & $\boldsymbol{\Delta}_{\mathbf{c}-\mathbf{8}}$ \\
\hline 50 & 8.22 & 11.5 & 13.03 & 13.15 \\
100 & 6.45 & 9.04 & 10.25 & 10.4 \\
200 & 5.12 & 7.17 & 8.14 & 8.32 \\
300 & 4.56 & 6.39 & 7.27 & 7.46 \\
\hline
\end{tabular}

Based on regression analysis, a mathematical function is proposed to obtain the best fitting saturated shear strength attenuation rate with drying-wetting cycle samples. The mathematical equation is-

$$
\Delta_{\tau}=\mathrm{J}_{0}-\frac{\mathrm{J}_{0}}{\left(1+\frac{\mathrm{N}}{\mathrm{J}_{1}}\right)^{\mathrm{J}_{2}}}
$$

Where, $\Delta_{\mathrm{t}}$ is saturated shear strength attenuation rate, $\mathrm{N}$ is the drying-wetting cycle number and $\mathrm{J}_{0}, \mathrm{~J}_{1} \& \mathrm{~J}_{2}$ are fitting parameters. The variations of fitting parameters $\left(\mathrm{J}_{0}, \mathrm{~J}_{1} \& \mathrm{~J}_{2}\right)$ with respect to different net normal stress $\left(\sigma-\mu_{\mathrm{a}}\right)$ can be calculated by the following equations-

$$
\begin{aligned}
& \mathrm{J}_{0}=7.2128+10.7652 \exp \left[-0.012\left(\sigma-\mu_{\mathrm{a}}\right)\right] \\
& \mathrm{J}_{1}=-2.5494-5.36 \exp \left[0.0066\left(\sigma-\mu_{\mathrm{a}}\right)\right]
\end{aligned}
$$

$$
\mathrm{J}_{2}=-2.1357-5.1727 \exp \left[0.0065\left(\sigma-\mu_{\mathrm{a}}\right)\right]
$$

Using the above mathematical function, the predicted attenuation rate of saturated shear strength with respect to different drying-wetting cycles and net normal stresses are fitted well with the calculated data (Fig. 19). The correlation coefficients are more than $99 \%$, indicating that the proposed mathematical function can describe the attenuation rate of drying-wetting cycle samples saturated shear strength.

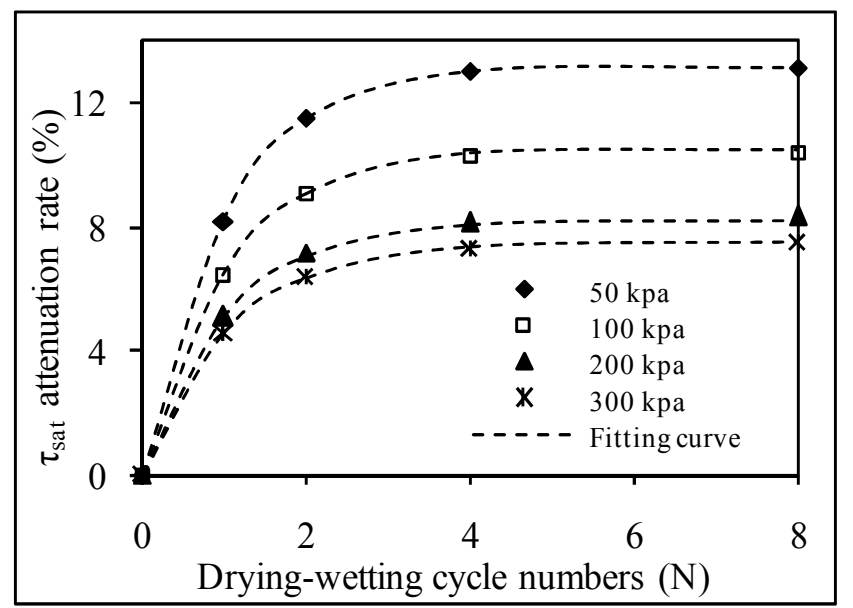

Figure 19. Fitting curves of $\tau_{\text {sat }}$ attenuation rate (\%) under drying-wetting cycles.

\section{Conclusion}

In this study, the effects of multiple drying-wetting cycles on saturated shear strength of undisturbed residual soil are investigated using a series of consolidated drained triaxial tests. The stress-strain curves for the drying-wetting cycle samples appear to be strain-hardening. The deviatory stress and initial stiffness of saturated soils increase with increasing net normal stress but decrease with increasing drying-wetting cycle numbers. The axial strains to attain maximum deviator stress for these drying-wetting samples show higher values range from $14.57-18.94 \%$ which is a reflection of highly plastic nature of the soil. The slope of the critical state line decreases with increasing cycle numbers. The cohesion $\left(c_{d}\right)$ and internal friction angle $\left(\varphi_{d}\right)$ decrease with increasing cycle number $(\mathrm{N})$ but the attenuation rate of $\varphi_{d}$ is less than $c_{d}$. The variations of $c_{d}$ and $\varphi_{d}$ with respect to drying-wetting cycles can be expressed by exponential function. The saturated shear strength of residual soil decreases with increasing number of cycles. The effect is more significant for the first cycle and decreases with subsequent cycles and finally reaches to a constant state after 4 cycles. The attenuation rate of shear strength due to drying-wetting cycles is also analyzed. Furthermore, a mathematical function is proposed in this paper which can describe the saturated shear strength attenuation rate of drying-wetting cycle samples. Such studies are useful to understand the possible changes in shear strength behavior of residual soil that are subject to periodic drying and wetting from climatic variations and may provide the reference to the future geotechnical engineers and disaster 
reduction professionals to build up engineering structures safely and economically.

\section{Acknowledgements}

The authors would like to acknowledge financial support from the National Natural Science Foundation of China (Grant No. 41372314) and the Science and Technology Service Network Initiative of the Chinese Academy of Sciences (Grant No. KFJ-EW-STS-122). The first author gratefully acknowledges the $\mathrm{PhD}$ scholarship from CAS-TWAS President's Fellowship Programme.

\section{References}

[1] P. R. Vaughan, M. Maccarini and S. M. Mokhtar, "Indexing the engineering properties of residual soil," Quarter. Jour. Eng. Geol., vol. 21, 1988, pp. 69-84.

[2] L. D. Wesley, Geotechnical Engineering in Residual soils, Jonh Wiley \& Sons, Inc., USA, 1990.

[3] P. G. Fookes, Tropical residual soils (Ed.), The Geological Society Publishing House, U. K., 1997.

[4] A. T. M. S. Hossain, "The engineering behaviour of the tropical clay soils of Dhaka, Bangladesh," Durham theses, Durham University, 2001 (Available at Durham E-Theses Online: http://etheses.dur.ac.uk/3792).

[5] H. Rahardjo, K. K. Aung, E. C. Leong and R. B. Rezaur, "Characteristics of residual soils in Singapore as formed by weathering,” Eng. Geol., vol. 73 (1-2), 2004, pp. 157-169.

[6] H. X. Lana, R. L. Hu, Z. Q. Yue, C. F. Leek and S. J. Wang, "Engineering and geological characteristics of granite weathering profiles in South China," Jour. Asian Earth Sci., vol. 21, 2003, pp. 353-364.

[7] I. Jworchan, "Mineralogy and chemical propertries of residual soils," IAEG, No. 21, 2006.

[8] Y. E. -A. Mohamedzein and M. H. Aboud, "Compressibility and shear strength of a residual soil," Geotech. Geol. Eng., vol. 24, 2006, pp. 1385-1401.

[9] H. Rahardjo, F. Melinda, E. C. Leong and R. B. Rezaur, "Stiffness of a compacted residual soil," Eng. Geol., vol. 120, 2011, pp. 60-67.

[10] M. Kumruzzaman and J. Yin, "Stress-Strain Behaviour of Completely Decomposed Granite in both Triaxial and Plane Strain Conditions," Jordan Jour. Civil Eng., vol. 6 (1), 2012, pp. 83-108.

[11] F. A. M. Marinho, O. M. Oliveira, H. Adem and S. Vanapalli, "Shear strength behavior of compacted unsaturated residual soil,” Inter. Jour. Geotech. Eng., vol. 7 (1), 2013.

[12] M. M. Allam and A. Sridharan, "Effect of wetting and drying on shear strength," Jour. Geotech. Eng., vol. 107 (GT4), 1981, pp. $421-438$.

[13] K. Sobhan and B. M. Das, "Durability of soil-cements against fatigue fracture," Jour. Mater. Civ. Eng., vol. 19 (1), 2007, pp. $26-32$.
[14] O. Cuisinier and F. Masrouri, "Hydromechanical behavior of a compacted swelling soil over a wide suction range," Eng. Geol., vol. 81, 2005, pp. 204-212.

[15] S. M. Rao and K. Revanasiddappa, "Influence of cyclic wetting drying on collapse behavior of compacted residual soil," Jour. Geotech. Geol. Eng., vol. 24, 2006, pp. 725-734.

[16] S. Tripathy, S. Kanakapura and S. Rao, "Cyclic swell-shrink behavior of a compacted expansive soil," Geotech. Geol. Eng., vol. 27, 2009, pp. 89-103.

[17] J. C. B. Benatti, M. G. Miguel, R. A. Rodrigues and O. M. Vilar, "Collapsibility study for tropical soil profile using oedometric tests with controlled suction," In: Alonso, E. E. \& Gens, A. (Eds.), Proceedings of the $5^{\text {th }}$ international conference on unsaturated soils, Taylor \& Francis Group, London, 2011, pp. 193-198.

[18] R. D. Tovar and J. E. Colmenares, "Effects of drying and wetting cycles on the shear strength of argillaceous rocks," In: Alonso, E. E. \& Gens, A. (Eds.), Proceedings of the $5^{\text {th }}$ international conference on unsaturated soils, Taylor \& Francis Group, London, 2011, pp. 1471-1476.

[19] M. Kholghifard, K. Ahmad, N. Ali, A. Kassim and R. Kalatehjari, "Collapse/Swell Potential of Residual Laterite Soil Due to Wetting and Drying-wetting Cycles," Natl. Acad. Sci. Lett., vol. 37, 2014, pp. 147-153.

[20] D. A. Sun, and D. J. Huang, "Soil-water and deformation characteristics of Nanyang expansive soil after wetting-drying cycles," Rock Soil Mech., vol. 36, 2015, PP. 115-119 (in Chinese)

[21] P. H. Morris, J. Graham and D. J. Williams, "Cracking in drying soils," Can. Geotech. Jour., vol. 29, 1992, pp. 263-277.

[22] B. A. Albrecht and C. H. Benson, "Effect of desiccation on compacted natural clays," Jour. Geotech. Geoenviron., vol. 127, 2001, pp. 67-75.

[23] K. Harishkumar and K. Muthukkumaran, "Study on swelling soil behaviour and its improvements," Int. Jour. Earth Sci. Eng., vol. 4, 2011, pp. 19-25.

[24] Y. Wan, Q. Xue, L. -Y, Zhao, Y. -J. Du and L. Liu, "Effects of wetting-drying cycles on permeability of compacted clay cover at landfill site" Rock Soil Mech., vol. 36 (3), 2015, pp. 679-693 (in Chinese).

[25] F. Akcanca and M. Aytekin, "Impact of wetting-drying cycles on the hydraulic conductivity of liners made of lime-stabilized sand-bentonite mixtures for sanitary landfills," Environ. Earth Sci., vol. 72, 2014, pp. 59-66.

[26] Z. T. Zeng, H. B. Lu and Y. L. Zhao, "Wetting-Drying Effect of Expansive Soils and its Influence on Slope Stability," Appl. Mecha. Material, vol. 170-173, 2012, pp. 889-893.

[27] J. Zhou, H. Z. Xu and W. J. Hu, "Impact of wetting-drying cycle effects on stability of expansive soil slopes," Chin. Jour. Geotech. Eng., vol. 35 (zk2), 2013, pp. 152-156 (in Chinese).

[28] A. A. Basma, A. S. Al-Homoud, A. I. Husein-Malkawi and M. A. Al-Bashabsheh, "Swelling-shrinkage behavior of natural expansive clays," Appl. Clay Sci., vol. 11, 1996, pp. 211-227.

[29] S. Tripathy, K. S. Subba Rao and D. G. Fredlund, "Water content-void ratio swell-shrink paths of compacted expansive soils," Can. Geotech. Jour., vol. 39, 2002, pp. 938-959. 
[30] F. J. Leij, T. A. Ghezzehei and D. Or, "Modelling the dynamics of the soil pore-size distribution," Soil Tillage Res., vol. 64, 2002, pp. 61-78.

[31] L. Li, W. Zhu, C. Lin and T. Ohki, "Study of wet and dry properties of solidified sludge," Rock Soil Mech., vol. 30 (10), 2009, pp. 3001-3004 (in Chinese).

[32] C. Yang, F. Zha and K. Cui, "Effect of cyclic wetting and drying on the engineering properties of stabilized expansive soils," Indust. Constr., vol. 42 (1), 2012, pp. 98-103 (in Chinese).

[33] C. -S. Tang, D. -Y. Wang, B. Shi and J. Li, "Effect of wetting-drying cycles on profile mechanical behavior of soils with different initial conditions," Catena, vol. 139, 2016, pp. $105-116$.

[34] D. -Y. Wang, C. -S. Tang, Y. - J. Cui, B. Shi and J. Li, "Effects of wetting-drying cycles on soil strength profile of a silty clay in micro-penetrometer tests," Eng. Geol., vol. 206, 2016, pp. 60-70.

[35] ASTM D7181-11, Method for Consolidated Drained Triaxial Compression Test for Soils, ASTM International, West Conshohocken, PA, 2011. 